\title{
La invisibilitat com a matèria política: Vermell de Cadmi de Margarida Aritzeta i Los invisibles de José María Merino
}

\author{
Invisibility as a political matter: Vermell de Cadmi \\ by Margarida Aritzeta, and Los invisibles \\ by José María Merino ${ }^{1}$
}

\author{
Alfons Gregori \\ Uniwersytet im. Adama Mickiewicza w Poznaniu \\ alfons@amu.edu.pl
}

\begin{abstract}
Invisibility is the main motif of two non-mimetic novels belonging to the Catalan and Spanish literature respectively: Vermell de Cadmi [Cadmium Red] (1984) by Margarida Aritzeta, and Los invisibles [The Invisible] (2000) by José María Merino. The aim of the present article is to compare both novels by analysing how the dialectical process between body, fantasticality, and social conflict works in them, taking into account their historic and literary contexts, possible interpretations of the unusual events from an ideological point of view, and the strategies used for achieving the fantastic effect in both of them.
\end{abstract}

Keywords: Spanish fantastic literature, Catalan science fiction, José María Merino, Margarida Aritzeta, invisibility in literature, ideology in literature

\section{PRESENTACIÓ: TEXTOS I CONTEXTOS}

En el marc de la literatura contemporània, la novel·la de ciència-ficció de H. G. Wells The Invisible Man, apareguda l'any 1897, va suposar una fita en l'ús del

\footnotetext{
${ }^{1}$ Aquest treball s'inscriu en el projecte Lo fantástico en la cultura española contemporánea (19552017): narrativa, teatro, cine, TV, cómic y radio (FFI2017-84402-P).
} 
motiu de la invisibilitat, que ha estat adoptat i reinterpretat en multitud d'obres literàries $\mathrm{i}$ fílmiques. ${ }^{2}$ En l'obra esmentada destaca la qüestió del poder que atorga la condició d'invisibilitat, en aquest cas vista des d'una perspectiva que contraposava individu i societat. Dos exemples de reelaboració d'aquest motiu que problematitzen d'una manera força més polièdrica la dicotomia entre subjecte i comunitat, alhora que es desplacen parcialment o completa envers la literatura fantàstica, són les dues novel·les que seran objecte d'estudi en aquest treball, escrites en diferents moments històrics $\mathrm{i}$ en dues llengües diferents, tot i que en veïnatge permanent: Vermell de cadmi (1984), de l'escriptora de Valls Margarida Aritzeta (1953), i Los invisibles (2000), de l'autor lleonès José María Merino (1941). En l'article s'analitzaran comparativament les dues novel-les esmentades amb l'objectiu de presentar la dialèctica entre cos, fantasticitat i conflicte social que s'hi planteja, tenint en compte el context històric i literari, les interpretacions ideològiques de l'insòlit, així com les estratègies de l'efecte fantàstic en totes dues.

Aritzeta és una escriptora amb una prolífica carrera literària. Encara que no hagi aconseguit introduir-se en el cànon de la literatura catalana contemporània, està present en diversos estudis panoràmics sobre la matèria. ${ }^{3}$ Així, Julià (2008) situa Aritzeta en el grup d'autores que, sense formar-ne part, s'afegeix al "gruix generacional" que aflora bàsicament als anys $70 \mathrm{i}$ que desenvolupa "[...] amb normalitat - $\mathrm{i}$ en alguns casos amb èxits assenyalats- la seva obra al llarg dels anys vuitanta i noranta: obtenen premis, les editorials promocionen la seva obra i els diaris publiquen articles de crítica favorables" (p. 10). D'altra banda, Cortés Orts i Gisbert López (2015) l'esmenten com una dels autors i autores "de renom" de finals dels 70 $\mathrm{i}$ inicis dels 80 (p. 68). La major part de la narrativa d'Aritzeta se cenyeix a l'estil realista, si bé en els seus inicis i posteriorment va publicar algunes obres en què

\footnotetext{
${ }^{2}$ Aquesta obra té un llarg recorregut en la tradició literària moderna dins de l'Estat espanyol, ja que ha estat reiteradament traduïda tant al castellà com al català (en les versions inicials sovint sense que s'esmentés el nom del traductor en l'edició). Entre d'altres, caldria esmentar la publicació de la novel·la l'any 1905 de la mà de Ramón Orts-Ramos o la traducció de 1953 de Julio Gómez de la Serna, en el cas espanyol, mentre que Just Cabot la va portar al català l'any 1929 i, més recentment, l'any 2008, també va ser traduïda per Laura Brasó. Per a una detallada consideració sobre la importància de Barcelona en la difusió de Wells a la Península, a més de la repercussió que va tenir la seva obra en les lletres catalanes, v. Iribarren i Donadeu (2005). Abans de presentar el debat ideològic suscitat per L'home invisible en els cercles intel·lectuals catalans, la investigadora subratlla la importància de la novel la en aquell context: "the Catalan translation of The Invisible Man (1929) had a real impact and initiated the epoch when Well's presence was most strongly felt in Catalonia. [...] To begin with, The Invisible Man elicited the first general acceptance of Well's literary qualities" (Iribarren i Donadeu, 2005, p. 226).

${ }^{3}$ Aritzeta apareix esmentada, per exemple, a l'estudi panoràmic de Real (2005, p. 79) sobre les narradores catalanes del s. XX que forma part del volum col·lectiu Escriptores: de Caterina Albert als nostres dies. Tanmateix, no va ser inclosa a Els altres mons de la literatura catalana, el volum de literatura fantàstica i especulativa elaborat per Martínez-Gil, ni se'n parla a la introducció que l'encapçala.
} 
s'endinsava en la creació literària no mimètica, com Grafèmia (1982), Atlàntida (1995) o la mateixa Vermell de Cadmi. Malgrat la seva llarga trajectòria literària, tot just s'han publicat uns pocs treballs acadèmics que estudien $i$ aprofundeixen en l'obra de Aritzeta, per bé que sempre hi ha hagut una recepció crítica present a la premsa periòdica, que s'ha incrementat en els últims anys coincidint amb una nova etapa de fructífera creació basada en el gènere de la novel·la negra i la recreació ficcional de temes vinculats a la memòria històrica. D'altra banda, en el marc de la seva tasca de professora universitària ha estat una investigadora inquieta $i$ ha bastit una substanciosa obra de recerca en base a sòlids coneixements de teoria literària, especialment a l'entorn d'aspectes de la ficció narrativa, com la teoria dels mons possibles o la intertextualitat. ${ }^{4}$ Aquest interès no resulta gens aliè a la seva tasca de creació literària, ${ }^{5}$ tot i que cal relativitzar-lo en el cas de l'obra que ens ocupa, perquè va ser publicada en una època en què la fase d'investigació d'Aritzeta estava en procés germinal.

A Vermell de cadmi es desenvolupen qüestions presents en obres d'altres membres del col-lectiu Ofèlia Dracs, actiu bàsicament durant els anys $80 \mathrm{i}$ del qual formava part l'escriptora vallenca. Com afirma Martínez-Gil (2004): "sota l'exemple de Manuel de Pedrolo, els autors d'Ofèlia Dracs veuran la literatura de gènere com una manera d'introduir la literatura catalana en el consum popular" (p. 37). Aritzeta es va integrar en el col-lectiu amb el repte, doncs, d'apostar per la diversificació literària mitjançant una narrativa de gènere de qualitat que omplís el buit existent de literatura policíaca, fantàstica, de ciència-fícció, de terror o eròtica en llengua catalana. ${ }^{6}$ En són una bona mostra dos reculls que duen uns títols gens enigmàtics per als amants de la literatura no mimètica: Lovecraft, Lovecraft! (1981) i Essa efa (1985), el primer centrat en el terror i l'efecte fantàstic, i el segon, en la narrativa especulativa i de ciència-ficció. ${ }^{7}$ Paral-lelament, i també com a herència pedroliana, el plantejament polític dels seus membres era molt clar: contribuir amb la seva tasca literària $\mathrm{i}$ intel·lectual a l'assoliment d'una societat més progressista i d'esquerres, atenent la normalització de l'ús públic del català i proposant l'adopció de mesures per aconseguir l'emancipació real de les dones. I, en els albors del desenvolupament de la democràcia representativa a l'Estat, es mostraven força crítics amb les

\footnotetext{
${ }^{4}$ En l'actualitat Aritzeta és Catedràtica d'Escola Universitària de teoria de la literatura i literatura comparada al Departament de Filologia Catalana de la Universitat Rovira i Virgili. Recentment ha anunciat la seva jubilació. Val a dir que és l'autora d'un Diccionari de termes literaris (1996).

5 "Des de sempre he entès la literatura com un joc entre textos, entre discursos, com deia Barthes. I m'agrada que uns textos portin a uns altres, s'hi relacionin, hi dialoguin, que el lector tingui la sensació que la literatura no s'acaba en un llibre, que no s'acaba mai" (Villalonga, 2016).

${ }^{6}$ Fins i tot Jaume Cabré -avui reconegut com a autor plenament realista- es va recrear en la narrativa breu de caràcter fantàstic dins del col-lectiu Ofèlia Dracs.

${ }^{7}$ Aritzeta és l'autora del relat de ciència-ficció "La fi de Medusa-3" que apareix a Essa efa (comunicació personal, 15 de gener, 2018).
} 
estructures de poder que romanien o s'adaptaven lampedusianament als nous temps. En aquest sentit, a Vermell de cadmi es poden observar de manera singular les pulsions d'alliberament sociopolític, nacional i sexual que es van viure a Catalunya en la Transició.

El fenomen assenyalat de diversificació de gèneres no és privatiu de les lletres catalanes, ja que en la literatura espanyola la revalorització d'aquestes modalitats literàries va conduir a un augment de la seva producció. En efecte, ho adverteix el mateix Merino (2014, p. 59): "no puedo entender el cambio literario desde la muerte de Franco sino a través de la irrupción de elementos de los géneros y subgéneros, no considerados tradicionalmente como nobles dentro del trabajo literario". L'autor de Los invisibles és un reconegut autor de literatura fantàstica, a la qual ha dedicat la major part de la seva obra de creació. ${ }^{8}$ Desenes d'articles acadèmics i centenars de ressenyes crítiques sobre els seus llibres han anat apareixent a mesura que la seva popularitat $\mathrm{i}$ el seu prestigi augmentaven entre el públic lector, inclosos els hispanistes $\mathrm{i}$ investigadors en literatura no mimètica de l'àmbit hispanòfon. Merino i Aritzeta van iniciar les seves respectives carreres com a narradors gairebé en el mateix període, ${ }^{9}$ ja que la Novela de Andrés Choz de l'autor espanyol va veure la llum l'any 1976, només quatre anys abans que Aritzeta rebés el premi Víctor Català de contes i narracions per la seva opera prima, el recull Quan la pedra es torna fang a les mans (1981).

No obstant, la novel·la de Merino seleccionada, Los invisibles, és bastant posterior a Vermell de cadmi, ja que va ser publicada setze anys més tard. En conseqüència, l'obra del lleonès va irrompre en el mercat literari amb un context polític força diferent al d'aquell en què va veure la llum la novel·la d'Aritzeta. Així, el govern socialista de Felipe González havia estat substituït per la dreta del Partit Popular, després del fort descrèdit sofert per la corrupció a gran escala que afectava al PSOE i per les trames de terrorisme d'estat denunciades públicament. En la primera legislatura del govern d'Aznar va endurir-se la liberalització del mercat laboral ja iniciada prèviament amb l'ocàs socialista $\mathrm{i}$ es va dur a terme el desmantellament del monopoli estatal en certs sectors, entre d'altres mitjançant la privatització d'empreses. No debades, doncs, a Espanya es feia cada cop més palès el temor a una regressió en els avenços socials. En l'àmbit internacional s'acumulaven notícies que evidenciaven el fracàs del model occidental i augmentaven aquells temors esmentats més amunt: el món havia estat testimoni de les atroces massacres a Iugoslàvia davant la passivitat i inoperància de les autoritats de la Unió Europea, i s'havien

\footnotetext{
${ }^{8}$ De fet, Carrera Garrido (2017, p. 96) explicita que l'admissió de Merino en el cànon literari espanyol es basa en les contribucions de l'autor a la modalitat del fantàstic. Per a un panorama biobibliogràfic de l'escriptor lleonès, v. Alonso (2012, p. 9-39).

${ }^{9}$ De fet, Merino va iniciar la seva trajectòria com a escriptor a principis dels anys 70 en el marc de la creació poètica, però va abandonar aquest camí en aquella mateixa època per centrar-se en la producció en prosa.
} 
passat dècades de vergonya contemplant amb impotència com diversos països d'Àfrica es veien delmats per unes fams que cap campanya no era capaç d'eradicar. De fet, Merino (2014) ha remarcat en més d'una ocasió el paper de les obres literàries en la conscienciació política de llurs consumidors: "en lo que, se diga lo que se diga, han sido conquistas de la libertad humana -laicismo, secularización, derechos individuales, democratización de la sociedad...- la literatura ha jugado un papel decisivo" (p. 159).

En totes dues novel-les els narradors fan referència de manera més o menys explícita als contextos sociopolítics de sengles temps d'escriptura. En l'obra de Merino s'empren al-lusions concretes que funcionen a mode de l'effet de réel de Barthes i que serveixen per donar cos al fons de versemblança realista, el qual al seu torn contrasta amb el fenomen irreal i realça, així, la fantasticitat del text. ${ }^{10} \mathrm{De}$ qualsevol manera, resulta curiosa la tendència en ambdós textos a invisibilitzar els topònims dels llocs en què es desenvolupa l'acció. Si en la novel·la catalana només apareix algun gentilici escàs -alhora que esmenta detalladament indrets de Suïssa que formen part de la història- i s'hi parla del "nostre país" i de "la nostra llengua" tot cercant la reacció empàtica dels lectors, a Los invisibles l'ocultació sembla voler incrementar el misteri de la narració - tot compensant la nitidesa amb què s'hi relata la manifestació del motiu fantàstic- i la participació activa dels lectors que coneixen mínimament el recorregut biogràfic de l'escriptor lleonès. ${ }^{11}$

\section{HISTÒRIES D'ÉSSERS INVISIBLES: IDENTITAT, CRÍTICA SOCIAL I MODALITATS LITERÀRIES}

La novel-la espanyola parteix d'un fenomen impossible: la nit de Sant Joan l'Adrián, un noi que camina pel bosc, esdevé invisible pels efectes d'una misteriosa flor blava (Merino, 2012, p. 95-97). Ell i la Bruna, protagonistes de les respectives novel-les analitzades, comparteixen un tret important: la joventut. Ambdós es troben en una fase en què ja han completat llur formació fonamental i inicien allò que podem anomenar la carrera de la vida, és a dir, un moment de canvi davant d'un horitzó de possibilitats que, d'acord amb els relats respectius, esdevenen reptes vitals

\footnotetext{
${ }^{10}$ La novel·la és, globalment, un gènere menys cultivat en la seva variant fantàstica que el relat breu, també en el període literari dins el marc espanyol en què va aparèixer Los invisibles (v. Roas, Álvarez \& García, 2017, p. 197), ja que resulta més complicat mantenir la tensió del fantàstic en un relat de certa extensió.

${ }^{11}$ Quan Alonso (2012) afirma que la localització dels espais en aquesta novel-la és fidel a la realitat (p. 51) generalitza la seva pròpia capacitat d'interpretació dels indicis que dona el narrador en lectors que no necessàriament han de saber-los interpretar. Les limitacions de l'asseveració de l'estudiós es perceben quan, tot tractant de l'espai a l'obra, es refereix al "Levante" i "la ciudad de Rosa" sense més concrecions (v. Alonso, 2012, p. 65).
} 
i experiències extraordinàries en la conformació de la seva actitud envers la realitat. A Vermell de cadmi Bruna Bononi és una periodista valenta que representa la decepció davant d'un procés de transformació política en què no només no s'aconsegueixen els objectius reivindicats per una sèrie d'activistes $\mathrm{i}$ intel·lectuals de l'esquerra catalanista, sinó que la dreta regionalista va ocupant posicions de poder i molts pretesos progressistes s'aburgesen en una meteòrica carrera política o funcionarial, amb aquella sensació de traïció al poble que amb tant d'encert va saber representar líricament Luis Eduardo Aute a "La belleza" (1989) i que Lluís Llach ja havia anunciat a "Companys, no és això" (1978). Bruna encaixa, doncs, amb la descripció dels personatges dels llibres que convencen Aritzeta: "[...] gent que batalla per coses i es queden atrapats en un mateix enigma" (Castells, 2010).

En la novel·la Bruna coneix Llorenç Grasses, un gris comercial que li relata una història increïble: assegura haver experimentat la pèrdua del cos durant unes setmanes per motius que ell llavors ignorava, la qual cosa va significar també la seva invisibilitat. En les dues obres, tanmateix, la vivència es col-lectivitza. Mentre que, en la novel·la espanyola, l'Adrián no és l'únic que deixa de ser visible a causa de la flor blava, perquè existeix tota una comunitat d'afectats amb la qual acaba entaulant relació -especialment amb la Rosa, la noia que esdevindrà la seva companya-, el Llorenç també se les campa amb altres víctimes del fenomen inexplicable. Cal assenyalar que els invisibles d'Aritzeta continuen sent visibles per a aquells que també han patit les conseqüències del fenomen i, a més, es veuen entre si amb el sexe invertit, és a dir, els homes són vistos com a dones i les dones com a homes. ${ }^{12}$ Alliberats de les necessitats fisiològiques i presentant sempre un aspecte escaient, no poden tocar-se ni tocar als altres perquè han esdevingut éssers totalment incorporis. Això els suposa un repte, i, com adverteix el propi Llorenç, han de tornar a aprendre a usar el seu cos (o el seu no-cos) provant noves formes de relacionar-se i de comportar-se amb un gènere en el qual no van ser educats o educades (Aritzeta, 1984, p. 79). Igualment, la narració posa èmfasi en les ganes d'experimentar nous mètodes eròtics que els permetin mantenir relacions sexuals. ${ }^{13}$ Ho aconsegueixen a través d'unes tècniques de concentració que podríem definir com a "tàntriques", o sigui, estrictament mentals, per bé que prou satisfactòries. D'aquesta manera es reactualitza la famosa frase de Simone de Beauvoir (1976), extreta del seu assaig Le Deuxième Sexe (1949): "on ne naît pas femme, on le devient" (p. 13), és a dir, el gènere

\footnotetext{
${ }^{12}$ McNerney (1988) comenta que a Vermell de cadmi es fa ús del canvi de sexe i d'una "sana dosi d'humor", de forma similar a allò que trobem a la novel·la El vaixell d'iràs $i$ no tornaràs, publicada l'any 1976 per una altra autora d'Ofèlia Dracs, la mallorquina Maria Antònia Oliver (p. 9-10).

${ }^{13}$ Aquest component eròtic de Vermell de cadmi encaixaria en part amb l'asseveració de Julià (2008) segons la qual durant la Transició diverses autores van rebre el reconeixement d'un "[...] ampli públic lector, primer àvid de llegir en català i de llegir sobre temes nous o vedats fins al moment, en què són centrals el sexe i les relacions amoroses no canòniques" (p. 10).
} 
és una condició que s'adquireix a través del procés de formació de la persona, fortament condicionat per factors externs.

En aquest sentit, en la novel·la d'Aritzeta els efectes del motiu fantàstic contrasten amb l'actitud inicial de Bruna, més aviat pessimista, ja que ofereixen una oportunitat a l'esperança d'alliberament i superació de les convencions socials i morals repressores imposades durant el franquisme. Així, un personatge mediocre com Llorenç passa de ser un avorrit comercial arrossegant un matrimoni que no el fa realment feliç a convertir-se en un il·lusionat somiador que persegueix fins a la mort la seva nova amant del món virtual. La conseqüència directa de tot plegat és que la dona l'abandona i s'emporta les filles. L'Adrián també pateix el rebuig de la família, i és al seu si que descobreix -ja abans de tornar-se invisible- alguns dels defectes que han caracteritzat la pitjor cara de la humanitat. A l'Adrián i al Llorenç, aquest rebuig els permet realitzar un exercici d'introspecció i maduresa, encara que sigui a costa d'esquinçar en certa manera la institució familiar. En el cas del personatge català, per bé que el "reaprenentatge" de gènere i la seva idílllica relació amb la companya d'aventures, l'Àloe, el condueixin a experiències irrepetibles, igual que a la resta d'afectats pel fenomen, aquest deixa de fer efecte de manera sobtada i natural, a diferència de la invisibilitat en l'obra de Merino. Així, als ex-incorporis d'Aritzeta, els arriba una mort ràpida: en pocs mesos pateixen un envelliment accelerat, situació que els porta a intentar unir-se per conèixer millor la malaltia $i$, si no és possible superar-la, morir plegats en un lloc tranquil i agradable. D'aquesta manera, el Llorenç esdevindrà un dels participants en el Primer Congrés d'Ex-Incorporis que se celebrarà a Mallorca. Aquesta faceta solidària i horitzontal del protagonista de Vermell de Cadmi, contrasta amb l'esforç de l'Adrián per tal d'actuar com el salvador de la seva comunitat un cop assabentat de la seva existència i de la llegenda que envolta la flor blava. Ho intenta fent equip amb la Rosa a la primera part de la novel·la ("La historia que contó Adrián"), i en solitari a la segona part ("Ni novela ni nivola"), quan malda per convèncer la projecció ficcional de Merino en l'obra de la necessitat d'escriure un llibre amb missatge que salvi tota la comunitat de la condemna a la invisibilitat.

La novel·la de Merino discorre per camins ja explorats en la narrativa de l'escriptor, com l'ús de la tradició popular en l'objectivació de l'impossible (la nit màgica de Sant Joan, per exemple). Ara bé, no es tracta d'un mer reciclatge de materials esgotats; com afirma Marta Simó (2007): “[...] desde el recurso de la metaficción, el autor recupera los temas, motivos y estrategias recurrentes en su narrativa para intelectualizarlos y desplegar, ante los ojos del lector, el mapa de su particular concepción de la literatura y del mundo" (p. 351). Òbviament, el motiu més destacat a l'obra és la invisibilitat, que serveix per dur a terme una reflexió més profunda sobre la identitat mateixa de l'individu:

[...] La invisibilidad constituye una de las modalidades prioritarias -tal vez la más impresionante- por las que José María Merino explora la identidad del ser humano, tema 
nuclear de toda su obra. En particular, al transformar a algunos de sus personajes en unos entes invisibles, no cabe duda de que procura significar la fragilidad o inestabilidad del sujeto contemporáneo, la dificultad de forjarse una identidad, o sencillamente de existir, en una sociedad compuesta de redes relacionales cada vez más complejas y móviles [...]. (Noyaret, 2015, p. 281) $)^{14}$

D’aquesta forma, la invisibilitat serveix de metàfora de la marginació social en diverses de les seves vessants: l'alienació que pateix el protagonista en un moment d'inestabilitat personal, ${ }^{15}$ un cop és conscient de la corrupció moral que rau en la seva relació amb la María Elena, la xicota oficial que l'enganya, i amb el món acadèmic, personificat en el prototípic director de tesi abusador; també la desídia davant les crisis humanitàries que afecten els països del Tercer Món, en relació tant a l'opressió dictatorial que solen patir -en el text es parla de Guinea-, com a la desatenció dels països rics envers els pobles d'Àfrica que, com denuncia la Rosa, agonitzen d'inanició; i, òbviament, també el "Quart Món”, és a dir, la vida paral·lela dels sensesostre, ignorats pels grups socials integrats en el sistema. Totes aquestes situacions són comparades en la novel·la de Merino amb el motiu de la invisibilitat d'una forma prou evident. ${ }^{16}$

Es tracta del particular homenatge de l'autor al descobriment dels Altres, els exclosos, els marginats. ${ }^{17}$ Ho sintetitza i desenvolupa el pensador argentí Bernardo Kliksberg (2014) en el seu estudi ¿Cómo enfrentar la pobreza y la desigualdad?, fent ús de la mateixa expressió figurada referida a l'invisible: "[...] aquellos que normalmente no tienen cómo llamar la atención ni hacerse sentir, no tienen peso

\footnotetext{
${ }^{14}$ El motiu de la invisibilitat també constitueix l'eix fonamental d'alguns relats de Merino, però la lectura del fenomen que s'hi fa s'allunya d'allò que es planteja en la novel·la aquí analitzada, ja que tracten més unívocament les fractures en la identitat del subjecte, un dels motius clàssics del fantàstic lligat al tema del doble i l'efecte ominós: “[...] en casos extremos, se llega incluso a plantear la total disolución del yo, ya sea mediante la transformación en otro ser o bien debido a la pérdida de su entidad física, a su desaparición, como ocurre, por ejemplo, en dos inquietantes relatos de Merino: «Las palabras del mundo» e «Imposibilidad de la memoria», ambos recogidos en El viajero perdido (1990)" (v. Roas, Álvarez \& García, 2017, p. 200). Giovannini (2001) estudia el motiu de l'evaporació corpòria com a metàfora de la pèrdua de la identitat als relats de Merino "La imposibilidad de la memoria" i "Las palabras del mundo".

${ }^{15}$ Per a un aprofundiment en la qüestió des d'un punt de vista psicològic, v. Simó (2007, p. 355360, 364-367).

${ }^{16}$ D'una manera més indirecta podem percebre aquesta denúncia de "la invisibilitat" dels mals i desgràcies que acompanyen l'existència de l'ésser humà contemporani al relat de Merino "Zarasia, la maga", en què l'única persona que sembla reaccionar realment a la brutalitat dels esdeveniments presentats al telenotícies pertany al primer mil·lenni de la nostra era.

${ }^{17}$ Així, Noyaret (2013) emfatitza el caràcter de denúncia sociopolítica i el missatge humanista que Merino hauria pretès transmetre a la novel·la, "[...] haciendo de la invisibilidad una metáfora de la miseria social y humana y de todas las formas de marginalidad y de exclusión, en su dimensión a la vez individual y colectiva" (p. 286).
} 
político ni están organizados, son los últimos, los «invisibles»” (p. 257). I, encara que el seu context d'escriptura no sigui el de la Transició, la novel·la de l'autor lleonès enllaça amb Vermell de cadmi, en el sentit que, com afirma encertadament Noyaret (2013), la veu narrativa aprofita per denunciar el discurs que idealitza aquest tipus de processos de transformació política, també a l'Estat espanyol (p. 287), ja que el mot "transició" sembla haver facilitat coartades que dissimulen o invisibilitzen la supervivència d'impostures (v. Merino, 2012, p. 279).

La invisibilitat funciona, doncs, com el reflex del problema d'un jo incomprès enfront de la societat com a massa dominant. En aquest sentit, es pot afirmar que es tracta de la culminació d'una elaboració literària sorgida del Romanticisme: la recreació d'un subjecte més o menys imbuït de projecció auctorial que considera la comunitat humana com una massa normativitzada aliena als interessos "autèntics" de l'existència, la qual cosa, des de Les desventures del jove Werther (1774) de Goethe, ha anat prenent formes diverses en la literatura contemporània. ${ }^{18}$ En aquest cas, però, caldria destacar la problematització de les relacions entre ciència i societat que comparteixen les obres d'Aritzeta i Merino. Si en l'autor lleonès es tracta d'un aspecte tractat reiteradament en els seus llibres, en el cas de la primera constitueix una de les línies fonamentals de Vermell de cadmi. Efectivament, l'insòlit en aquesta novel·la es construeix a partir de certes explicacions científiques, primer per la sospita que la invisibilitat es deriva d'uns experiments amb cadmi en ratolins, que hauria arribat als humans en forma de pastilla, i més endavant per la suposició que no són de fiar les notícies que atribueixen el fenomen dels incorporis al robatori de material radioactiu a Gran Bretanya. Així, la investigadora Kathleen McNerney (1988), per exemple, col·loca l'obra d'Aritzeta dins del calaix de la ciència-ficció (p. 10).

Tanmateix, alguns aspectes concrets fan trontollar aquesta adscripció unívoca, ${ }^{19}$ no sols en el cas de la novel·la catalana, sinó també en el del text de Merino. Així, la càrrega crítica que es desenvolupa en diversos moments del relat en contra de la manipulació informativa -recordem que Bruna és periodista- provoca dubtes raonables envers la credibilitat d'aquestes explicacions de base científica, detallades en dossiers que parlen de víctimes en set països europeus, amb les corresponents xifres. D'una banda, la protagonista $\mathrm{i}$ altres personatges desconfien de les expli-

\footnotetext{
${ }^{18}$ L'extensió limitada d'aquest estudi no permet aprofundir en les reminiscències kafkianes de 1'“anormalitat" de la societat que es perceben en la novel·la de Merino, en concret en la reacció dels familiars de l'Adrián quan perceben la seva transformació.

${ }^{19}$ La mateixa McNerney (1993) va matisar la classificació genèrica de la novel·la en un treball posterior: "[Vermell de cadmi] is fantastic and realistic at the same time, including political cover-ups, deceptions and blunders, and manipulations of the press, as well as physical transformations of certain people into invisible beings, persons whose gender changes and who age rapidly. At times approaching science fiction, this novel is also a platform to examine government control of our lives and sexism seen through the eyes of people who have known both genders" (p. 112).
} 
cacions del Llorenç sobre els efectes del canvi de sexe en aquest cos hologramàtic, considerant que són una al·lucinació o una ensarronada de qui ho explica; de l'altra, cap instància narrativa confirma les dades publicades per la premsa. A més, el procés d'envelliment és tan accelerat i produeix tal estat de beatífica senectut que fins al final del relat es manté una certa aura de misteri fantàstic. Respecte a Los invisibles, l'evident fantasticitat no està exempta de notes vinculades amb la ciènciaficció: no oblidem l'artificialitat aparent de la flor i les referències a l'electricitat o al concepte d" "irradiació" per tractar de definir les causes de la invisibilitat, així com la investigació mèdica a la qual és sotmesa Rosa quan la tanquen a l'hospital (v. Merino, 2012, p. 95-96, 140, 169), que també semblen més pròpies de la literatura especulativa que del fantàstic estricte. Si bé per als lectors que no han penetrat en les distincions acadèmiques de modalitats literàries aquestes disquisicions poden semblar poc consistents, els especialistes han determinat sovint que els fonaments del fantàstic i la ciència-ficció mantenen una relació d'oposició: "[...] la literatura fantástica se encuentra más alejada de la ciencia fícción que el hiperrealismo decimonónico, en la mayor parte de los casos" (Moreno, 2010, p. 5). ${ }^{20}$

D'altra banda, la figura de la Bruna es pot interpretar com una alter ego de la mateix autora, Aritzeta, ja que reprodueix trets físics i de caràcter que posseïa en aquell temps. A més, els amics amb inquietuds intel-lectuals que acompanyen la Bruna en algun moment de la història apareixen sota els noms reals de col-legues de l'escriptora, la majoria vinculats a Ofèlia Dracs, com per exemple l'avui tan mediàtica Pilar Rahola. Per tant, l'obra conté un element metaliterari, un tret molt propi de l'experimentalisme narratiu dels 70 , encara que es podria llegir més aviat com un gest de complicitat al cercle íntim de recepció i als lectors informats. En canvi, la condició metaliterària de Los invisibles forma part de l'estructura mateixa de la novel·la, que gràcies a això discorre entre dos tipus de fantàstic: el clàssic i el contemporani. Així, d'una banda, en la història de la invisibilitat de l'Adrián ens trobem un relat expressat per un narrador heterodiegètic que presenta amb tarannà objectivista l'esdeveniment preternatural, malgrat que alhora conté elements que enllacen amb la ciència-ficció i el meravellós. ${ }^{21}$ De l'altra, en les dues parts següents

\footnotetext{
${ }^{20}$ Així, a diferència del fantàstic, que cerca en l'ambigüitat del fenomen impossible $\mathrm{i}$ en la inseguretat davant del desconegut l'efecte d'inquietud o de por, el tret essencial de la ciència-fícció és el caràcter de projecció que presenten els elements irreals que hi apareixen, com argumenta Fernando Ángel Moreno (2010): "no es tan importante que el aval científico sea verificable en el mundo «real», como la pretensión del autor y la consiguiente aceptación del lector de que los hechos presentados no conlleven una visión sobrenatural, extra-científica, de la realidad. Esto es, se busca una relación directa con la realidad, no una evasión de la misma" (p. 105). El mateix autor proposa la següent definició del gènere: "ficción proyectiva basada en elementos no sobrenaturales" (Moreno, 2010, p. 106). Per a una caracterització més detallada i articulada del fantàstic, v. Roas (2011).

${ }^{21}$ Trabado Cabado (2005) fa una lectura força aguda i argumentada de l'ús polièdric de la tècnica literària a Los invisibles, ús que té per objectiu trencar la lògica receptiva dels lectors i crear-los vacil·lacions a l'entorn del caràcter meravellós, fantàstic, cronístic o assagístic de l'obra.
} 
que completen l'obra -en què la veu narrativa homodiegètica és assumida explícitament per una instància textual identificable com un alter ego de Merino (v. Trabado Cabado, 2005, p. 299-300)- es relaten alguns episodis extraordinaris i misteriosos amb presència d'éssers invisibles, cosa que reforça la fantasticitat d'aquests esdeveniments. Alhora, el narrador, que es presenta com algú assenyat i raonable, subratlla en diverses ocasions el seu escepticisme envers la història explicada per l'Adrián. Així, encara que sembli paradoxal, el (pretès) rigor i to moderat del narrador porten al dubte sobre si, en efecte, va viure fenòmens que als nostres ulls serien senzillament impossibles. En conseqüència, aquí entraria en joc l'ambigüitat exigida pel fantàstic pur todorovià, és a dir, la vessant clàssica d'aquesta modalitat narrativa. És aquest intel-ligent joc de veus i perspectives un dels factors que situa Merino en el pla d'excel·lència literària dins de la creació fantàstica en llengua espanyola. ${ }^{22}$

\section{CONCLUSIONS}

Tant Aritzeta com Merino dominen a la perfecció el llenguatge literari en els seus respectius idiomes: són mestres d'estil a l'hora d'adaptar-se a diversos registres lingüístics en l'escriptura de prosa ficcional. D'aquesta manera, dos autors procedents de la perifèria dels seus respectius sistemes literaris -Merino de Lleó, Aritzeta del Camp de Tarragona- van optar per variants distintes de la literatura no mimètica a l'hora d'elaborar unes obres que tenen la invisibilitat com a motiu principal, justament la invisibilitat simbòlica que pateixen tants autors perifèrics en les seves respectives literatures. En ambdues novel·les la quasi absència de topònims comporta la desmaterialització dels espais on es desenvolupa la trama, d'acord amb la pèrdua de contorns visibles d'alguns dels protagonistes. Les dues obres coincideixen en el creixement personal d'aquests protagonistes que experimenten la invisibilitat, com un bé sorgit d'una configuració narrativa entre el meravellós, el fantàstic i la ciènciaficció. En aquest mateix sentit, tant en la novel·la d'Aritzeta com en la de Merino, l'entrada en el món de la invisibilitat comporta paradoxalment la revelació de realitats ignorades, silenciades, ofuscades pel discurs hegemònic. També cal remarcar-hi la funció d'alter ego que realitzen determinats personatges de les obres, posant de manifest que una de les intencions d'aquestes és recercar-hi la pròpia identitat ${ }^{23}$ en

\footnotetext{
${ }^{22}$ Resulta interessant la interpretació que fa Robledo Vega (2017) de la ingerència d'un alter ego de l'autor en determinades parts de Los invisibles, ja que atribueix a l'escriptor lleonés la reivindicació d'un greuge cultural mitjançant la metaficció: “[Merino] explica la complejidad que supone la invención de una novela fantástica ajustada a una sociedad tan rígida como la española, en la que el Realismo siempre ha ganado terreno a lo fantástico" (p. 30).

${ }^{23}$ Això ja ho afirmava Noyaret (2013, p. 288) en referència a Los invisibles: "no cabe duda de que es la clave de su propia identidad la que está buscando Merino cuando se dedica [...] a un vertiginoso juego especular entre el autor real y sus dobles literarios".
} 
un moment convuls, de transformació. Tanmateix, sembla que totes dues narracions assumeixen i reforcen un plantejament ben tradicional, com és la dualitat sexual heteronormativa. Així, la inversió de sexes/gèneres de Vermell de cadmi acaba suposant la recuperació de la noció de "la mitja taronja", idea que també es derivaria del fet que el nom "Adrián" pot remetre a "Adán" -vinculació antroponímica que la crítica ja havia assenyalat-, i això faria que en l'obra de Merino aquest personatge es retrobés amb la seva Eva (Rosa), amb la qual viu episodis amb reminiscències bíbliques.

Si bé Los invisibles presenta una elaboració dels plans ficcionals força més complexa i un major domini de les tècniques narratives, els trets del motiu fantàstic i les interpretacions potencials de tipus sociopolític apareixen força més pautades de cara a la seva recepció. En canvi, a Vermell de cadmi la simplicitat rau més aviat en la forma narrativa escollida, mentre que les idees que es plantegen al llarg del text sobre els efectes del fenomen irreal i les seves lectures ideològiques resulten, en general, més obertes i suggestives. En definitiva, les dues obres fan usos particulars de tècniques literàries que les ubiquen en l'era postmoderna i contribueixen a enriquir el ventall de construccions narratives en què la metaficció es conjumina amb la crítica política dins del marc de la creació no mimètica contemporània.

\section{AGRAÏMENTS}

Voldria dedicar aquest article als herois invisibles, la gent pacífica que resisteix amb coratge per reivindicar democràcia, llibertat i justícia. 


\section{REFERÈNCIES BIBLIOGRÀFIQUES}

Alonso, S. (2012). Introducción. Dins J. M. Merino, Los Invisibles (p. 7-71, S. Alonso, ed.). Madrid: Cátedra.

Aritzeta, M. (1984). Vermell de cadmi. Barcelona: Laia.

Beauvoir, S. de (1976). Le Deuxième Sexe II: l'expérience vécue. París: Gallimard.

Carrera Garrido, M. (2017). Narrativa 1960-1980. Dins D. Roas (dir.), Historia de lo fantástico en la cultura española contemporánea (1900-2015) (p. 71-98). Madrid \& Frankfurt am Main: Iberoamericana \& Vervuert.

Castells, A. (2010, 25 de març). Un tros de conversa amb Margarida Aritzeta. Avui Cultura, p. 3.

Cortés Orts, C. \& Gisbert López, I. (2015). La reivindicació de la situació de la dona en la Transició a través de la revista Canigó. Dins C. Mañas Viejo, M. Esquembre Cerdá, M. Moreno Seco \& N. Montesinos Sánchez (eds.), I Coloquio Internacional Haciendo historia: género y transición política "Transiciones en marcha" (p. 66-78). Alacant: Universitat d'Alacant.

Giovannini, M. A. (2001). La evaporación corpórea como metáfora de la pérdida de la identidad. Cuadernos de Narrativa, 6, 165-175.

Iribarren i Donadeu, T. (2005). An Approximation of H. G. Well's Impact on Catalonia. Dins P. Parrinder \& J. Partington (eds.), The Reception of H. G. Wells in Europe (p. 222-235). Londres \& Nova York: Thoemmes Continuum.

Julià, Ll. (2008). Dones i escriptures: construcció del discurs i legitimació en la literatura catalana actual. Literatures, segona època, 6, 9-27.

Kliksberg, B. (2014). ¿Cómo enfrentar la pobreza y la desigualdad? Una perspectiva internacional. San José: Editorial Universidad de Costa Rica.

McNerney, K. (1988). Introduction. Dins K. McNerney (ed.), On Our Own Behalf: Women's Tales from Catalonia (p. 1-20). Lincoln \& Londres: University of Nebraska Press.

— (1993). Aritzeta i Abad, Margarida. Dins G. Bleiberg, M. Ihrie \& J. Pérez (eds.), Dictionary of the Literature of the Iberian Peninsula, $A-K$ (p. 111-112). Westport: Greenwood Press.

Martínez-Gil, V. (2004). Introducció. Els somni de la literatura: un itinerari català. Dins V. Martínez-Gil (ed.), Els altres mons de la literatura catalana: antologia de narrativa fantàstica i especulativa (p. 9-44). Barcelona: Cercle de Lectors \& Galàxia Gutenberg.

Merino, J. M. (2012). Los invisibles (S. Alonso, ed.). Madrid: Cátedra.

- (2014). Ficción perpetua. Palencia: Menoscuarto.

Moreno, F. A. (2010). Teoría de la Literatura de Ciencia Ficción. Poética y Retórica de lo Prospectivo. Vitoria: Portal Editions.

Noyaret, N. (2015). Invisibilidad y monstruosidad en Los invisibles de José María Merino. Dins D. Roas (coord.), El monstruo fantástico: visiones y perspectivas (p. 277-290). Madrid: Aluvión.

Real, N. (2005). Les narradores catalanes del segle XX: una narrativa per a un nou segle. Dins Escriptores: de Caterina Albert als nostres dies (p. 69-81). Barcelona: Fundació Lluís Carulla.

Roas, D. (2011). Tras los límites de lo real: una definición de los fantástico. Madrid: Páginas de Espuma.

Roas, D., Álvarez, N. \& García, P. (2017). Narrativa 1980-2015. Dins D. Roas (dir.), Historia de lo fantástico en la cultura española contemporánea (1900-2015) (p. 195-214). Madrid \& Frankfurt am Main: Iberoamericana \& Vervuert.

Robledo Vega, L. M. (2017). Cuando la realidad traspasa la ficción: una muestra de la realidad quebradiza en Los invisibles de José María Merino. Dins R. Hernández Arias, G. Rivera Rodríguez \& M. T. del Préstamo (eds.), Nuevas perspectivas literarias y culturales II (II CIJIELC) (p. 21-31). Vigo: MACC-ELICIN. 
Simó, M. (2007). Del mundo alegórico al mundo ficcional: discurso y sentido en Los invisibles, de José María Merino. Bulletin of Spanish Studies: Hispanic Studies and Research on Spain, Portugal and Latin America, 84 (3), 349-367. Doi:10.1080/14753820701321763.

Trabado Cabado, J. M. (2005). Crónica de lo maravilloso: ficciones y escrituras intermedias en Los invisibles, de José María Merino. Dins I. Andres-Suárez, A. Casas \& I. D’Ors (eds.), José María Merino (p. 295-314). Madrid: Arco/Libros.

Villalonga, A. M. (2016, 29 de gener). Margarida Aritzeta: "m'agrada escriure des de registres diferents". Núvol. Consultat 1'11 de setembre de 2017 a https:/www.nuvol.com/entrevistes/ margarida-aritzeta-magrada-escriure-des-de-registres-diferents 